\title{
Profiling and quantitative evaluation of three Nickel-Coated magnetic matrices for purification of recombinant proteins: helpful hints for the optimized nanomagnetisable matrix preparation
}

\author{
Mohammad Reza Nejadmoghaddam ${ }^{1 \dagger}$, Mahmood Chamankhah ${ }^{1 \dagger}$, Saeed Zarei ${ }^{2}$ and Amir Hassan Zarnani ${ }^{1,3^{*}}$
}

\begin{abstract}
Background: Several materials are available in the market that work on the principle of protein magnetic fishing by their histidine (His) tags. Little information is available on their performance and it is often quoted that greatly improved purification of histidine-tagged proteins from crude extracts could be achieved. While some commercial magnetic matrices could be used successfully for purification of several His-tagged proteins, there are some which have been proved to operate just for a few extent of His-tagged proteins. Here, we address quantitative evaluation of three commercially available Nickel nanomagnetic beads for purification of two His-tagged proteins expressed in Escherichia coli and present helpful hints for optimized purification of such proteins and preparation of nanomagnetisable matrices.

Results: Marked differences in the performance of nanomagnetic matrices, principally on the basis of their specific binding capacity, recovery profile, the amount of imidazole needed for protein elution and the extent of target protein loss and purity were obtained. Based on the aforesaid criteria, one of these materials featured the best purification results (SiMAG/N-NTA/Nickel) for both proteins at the concentration of $4 \mathrm{mg} / \mathrm{ml}$, while the other two (SiMAC-Nickel and SiMAG/CS-NTA/Nickel) did not work well with respect to specific binding capacity and recovery profile.

Conclusions: Taken together, functionality of different types of nanomagnetic matrices vary considerably. This variability may not only be dependent upon the structure and surface chemistry of the matrix which in turn determine the affinity of interaction, but, is also influenced to a lesser extent by the physical properties of the protein itself. Although the results of the present study may not be fully applied for all nanomagnetic matrices, but provide a framework which could be used to profiling and quantitative evaluation of other magnetisable matrices and also provide helpful hints for those researchers facing same challenge.
\end{abstract}

\section{Background}

After introduction of metal chelate affinity chromatography, a new approach to protein fractionation [1] and describing a new chelating matrix, Ni-NTA, for purification of fusion proteins containing histidine tags $[2,3]$, His-tag affinity purification has been widely used for the purification of recombinant proteins from various

\footnotetext{
* Correspondence: zarnani25@yahoo.com

+ Contributed equally

'Nanobiotechnology Research Center (NBRC), Avicenna Research Institute, ACECR, Tehran, Iran

Full list of author information is available at the end of the article
}

expression systems [4-6]. In recent years, a broad array of common support matrices with slightly different materials, magnetic properties, adsorbent particle size and shape, and spatially binding capacities and strengths have been introduced as tricky reagents for successful purification process of His-tagged proteins $[7,8]$.

With respect to these properties, the matrices offered by different commercial vendors differ very substantially from one another. Indeed, the choice of matrix is complicated by the fact that various suppliers offer practically the same particles under different names [7]. A collection of suppliers for nanomagnetic beads 
commonly used for the purpose of protein purification can be found in http://www.magneticmicrosphere.com/ suppliers/magnetic_microspheres.php.

Meanwhile, designing a purification procedure employing magnetisable solid phase support has become one of the interesting issues among chromatography reagents for His-tagged protein purification due to their less susceptibility to sample viscosity, convenience for scaling up and automation [9-18]. In these research reports and also commercially available manuals, little information is available on their performance, and it is often quoted that greatly improved purification of histidine-tagged proteins from crude extracts could be achieved. Although these statements may be true in some cases, the lack of well-suited optimized purification protocol based on Nickel-coated magnetic matrices may lead variable or even contrasting results for purification of His-tagged proteins and presents a major limitation for broad application of such materials. In this regard, optimization and evaluation of commercially available matrices is mandatory, which may result in uniform purification efficacy. Performance of such commercial magnetic matrices for purification of different His-tagged proteins is, therefore, required to be evaluated in terms of specific binding capacity, percent yield and recovery and reproducibility. Although several helpful hints have been proposed to obtain good results in magnetic separations of proteins and peptides [15], the full potential of these techniques has not been fully exploited. The present paper describes the evaluation and optimization of three newly-released magnetic beads namely: SiMAC-Nickel, SiMAG/N-NTA/Nickel and SiMAG/CS-NTA/Nickel for purification of two Histagged recombinant proteins, His-ProT and His-Mre11, overexpressed in Escherichia coli.

\section{Results}

\section{Relative expression of His-tagged recombinant proteins}

Recombinant proteins were extracted from IPTGinduced bacteria and their expression rates in the soluble fractions of cell lysate were determined by densitometric analysis as the percent of specific band to the all bands observed in SDS-PAGE gel. Accordingly, ProT and Mre11 relative expression rates were estimated to be about 25 and 19 percent, respectively (Figure 1 ).

\section{Evaluation of beads specific binding capacity}

At first, according to recommendation of the manufacturer, purification of His-tagged proteins was carried out based on the protocol supplied by Frenzel et al. [11] with $70 \mathrm{mg} / \mathrm{ml}$ of the beads and final elution of purified protein by $0.25 \mathrm{M}$ imidazole solution. By applying this protocol, most of the His-proteins remained attached to the beads after elution (data not shown) and this prompted us to

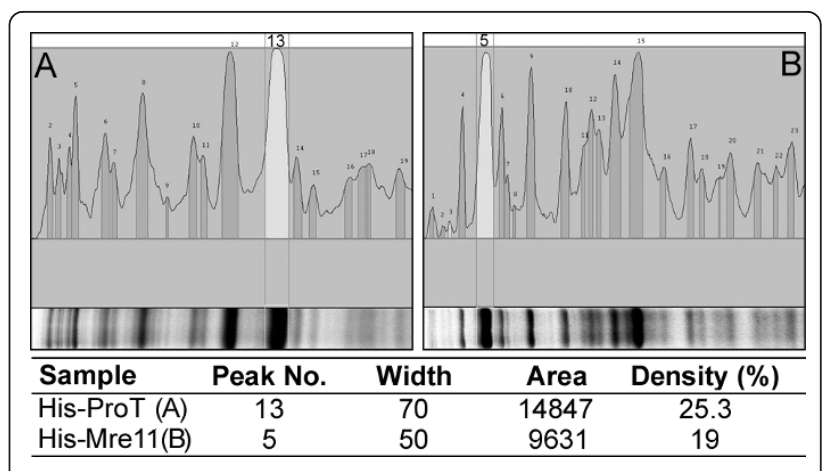

Figure 1 Densitometric analysis of recombinant protein expression. ProT (A) and Mre11 (B) recombinant proteins were expressed in E.coli and their relative expression in the soluble fraction of cell lysate were determined by densitometry using AlphaEase software

look for an optimized procedure to purify His-tagged proteins. The effect of the different magnetic beads concentrations (from 1 to $8 \mathrm{mg} / \mathrm{ml}$ for SiMAC-Nickel and from 0.5 to $8 \mathrm{mg} / \mathrm{ml}$ for SiMAG/N-NTA/Nickel and SiMAG/ CS-NTA/Nickel) on His-ProT and His-Mre11 specific binding capacity at $\mathrm{pH} 8.0,4^{\circ} \mathrm{C}$ was investigated by measurement of relative density of specific band in flowthrough (FT) fractions (Figure 2). In the range of bead concentration examined, maximum target proteins binding capacity was achieved at concentration of $8 \mathrm{mg} / \mathrm{ml}$ for all magnetic matrices examined (Figure 2 and Table 1). As shown in Figure 2, besides to proteins of interest, a number of non-target proteins was adsorbed non-specifically to SiMAC-Nickel beads and demonstrated a very similar trend of adsorption with increasing the concentration of the bead. As with His-tagged proteins, total content of non-specific proteins in FT decreased with increasing the concentration of SiMAC-Nickel beads indicating non-specific binding of non-target proteins in parallel to the target proteins. This pattern was not observed in the other two magnetic beads (Figure 2), where, content of target proteins in FT decreased considerably by increasing the concentration of the beads, whereas that of the contaminating proteins remained unchanged. Densitometric analysis of FT fractions revealed that three magnetic beads have different biding capacity and behave differentially as far as different His-tagged proteins are concerned. While SiMAC-Nickel and SiMAG/CS-NTA/Nickel specifically bound to both His-ProT and His-Mre11 proteins at comparable levels, the binding capacity of SiMAG/N-NTA/ Nickel beads to His-ProT was significantly greater than His-Mre11(Figure 3) ( $\mathrm{p}=0.016)$

\section{Protein yield and recovery}

In order to compare the efficacy of three magnetic/ Nickel beads in protein purification, two further indices 


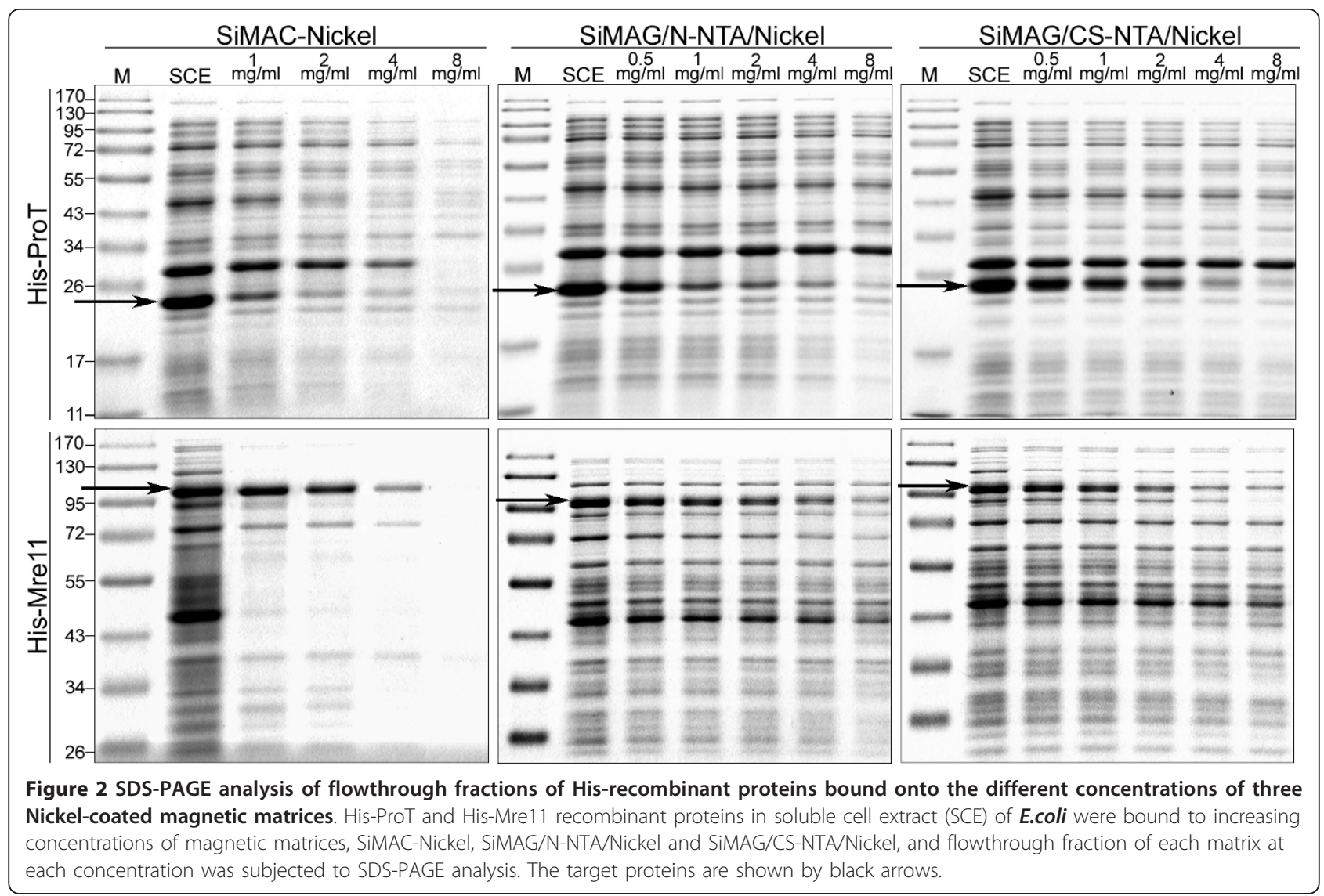

were evaluated. Yield and recovery percents were calculated as mentioned in methods. Interestingly, three matrices showed completely different purification efficacy as far as such variables as bead concentration, imidazole concentration, and the type of His-tagged protein were concerned (Table 1). The best purification result in terms of both yield and recovery percent was obtained for His-ProT when it was purified by $4 \mathrm{mg} / \mathrm{ml}$ of SiMAG/N-NTA/Nickel beads (Table 1 and Figure 4). The least efficacy of His-ProT purification was observed with SiMAG/CS-NTA/Nickel beads where a considerable amount of protein did not elute after four elution steps (Figure 4). Indeed, in comparison to other beads, SiMAG/CS-NTA/Nickel bead did not show reasonable specific binding capacity to this protein (Table 1 and Figure 4). These elution patterns were different from those of His-Mre11 protein, in which His-Mre11 protein was not purified at all by SiMAC-Nickel beads (Table 1 and Figure 5). In this case, approximately all bound proteins remained attached to the matrix even after elution with $2 \mathrm{M}$ concentration of imidazole (Table 1). Protein loss was considerably higher when His-Mre11 was purified by SiMAC-Nickel bead compared to the other beads (Figure 6) $(\mathrm{P}=0.014)$. Although, the highest recovery and yield for His-Mre11 were obtained when it was purified by $4 \mathrm{mg} / \mathrm{ml}$ of SiMAG/CS-NTA/Nickel bead (Table 1), the presence of nonspecific bands during the elution steps as judged by SDS-PADE (Figure 5) render it unsuitable for protein purification. Regarding the total protein loss for both proteins (Table 1), the SiMAG/N-NTA/Nickel bead was superior to the other beads.

\section{Effect of imidazole concentration}

According to the methods, proteins were eluted from SiMAC-Nickel beads by increasing concentrations of imidazole solution starting from $0.25 \mathrm{M}$ and continued till $2 \mathrm{M}$. Our preliminary data showed that neither HisMre11 nor His-ProT is eluted by lower concentrations of imidazole (data not shown). This condition was in contrast to what we observed in SiMAG/N-NTA/Nickel or SiMAG/CS-NTA/Nickel beads where elution was taken place with as low as $0.05 \mathrm{M}$ of imidazole solution. In this context, using SiMAG/N-NTA/Nickel bead, HisProT was eluted the most by 0.1 and $0.25 \mathrm{M}$ imidazole solution, while it remained attached to the SiMACNickel bead until higher concentration of imidazole (2 M) was used (Table 1). The results of the elution experiments with different concentrations of imidazole have been summarized in Table 1 and shown in Figure 5. As 
Table 1 Purification efficacy records of three Nickel-coated magnetic matrices for His-ProT and His-Mre11 recombinant proteins

\begin{tabular}{|c|c|c|c|c|c|c|c|c|c|c|}
\hline \multirow[t]{2}{*}{$\begin{array}{l}\text { Resin } \\
\text { type }\end{array}$} & \multirow[t]{2}{*}{ Protein type } & \multirow[t]{2}{*}{ Bead Concentration (mg/ml) } & \multirow[t]{2}{*}{$\begin{array}{l}\text { Specific binding capacity } \\
(\%)\end{array}$} & \multicolumn{4}{|c|}{$\begin{array}{c}\text { Relative band density } \\
(\%)\end{array}$} & \multirow[t]{2}{*}{$\begin{array}{l}\text { Yield } \\
\text { (\%) }\end{array}$} & \multirow[t]{2}{*}{$\begin{array}{l}\text { Recovery } \\
\text { (\%) }\end{array}$} & \multirow[t]{2}{*}{$\begin{array}{l}\text { Los: } \\
\text { (\%) }\end{array}$} \\
\hline & & & & $E_{1}$ & $E_{2}$ & $E_{3}$ & $\mathrm{E}_{4}$ & & & \\
\hline \multirow[t]{8}{*}{ SiMAC-Nickel } & His-ProT & 1 & 68.1 & 11.9 & 10.5 & 10.2 & 10.5 & 43.1 & 63 & 25 \\
\hline & & 2 & 91.5 & 12.6 & 16.3 & 21.7 & 27.8 & 78.4 & 86 & 13.1 \\
\hline & & 4 & 95.7 & 1.8 & 3.8 & 11.6 & 64.5 & 81.7 & 85 & 14 \\
\hline & & 8 & 98 & 0.5 & 0.6 & 1.1 & 66.2 & 68.4 & 70 & 29.6 \\
\hline & His Mre11 & 1 & 45.1 & 2 & 0.1 & 0 & 0.1 & 2.2 & 5 & 42.9 \\
\hline & & 2 & 46.9 & 2.1 & 0.1 & 0 & 0.1 & 2.3 & 5 & 44.6 \\
\hline & & 4 & 75.3 & 3 & 0.4 & 0 & 0.1 & 3.5 & 5 & 71.8 \\
\hline & & 8 & 88.1 & 3.6 & 0.9 & 0 & 0.1 & 4.6 & 5 & 83.5 \\
\hline \multirow[t]{10}{*}{ SiMAG/N-NTA/Nickel } & His-ProT & 0.5 & 50.4 & 17.8 & 12.8 & 1.6 & 0.4 & 32.6 & 65 & 17.8 \\
\hline & & 1 & 77.7 & 41.5 & 23.9 & 3.6 & 0.3 & 69.3 & 89 & 8.4 \\
\hline & & 2 & 82.8 & 29.2 & 37.8 & 9.4 & 1.1 & 77.5 & 93 & 5.3 \\
\hline & & 4 & 90.1 & 11.8 & 39.2 & 28.3 & 5.4 & 84.7 & 94 & 5.4 \\
\hline & & 8 & 93.3 & 6.5 & 34.2 & 32 & 7.7 & 80.4 & 86 & 12.9 \\
\hline & His Mre11 & 0.5 & 26.6 & 15.7 & 1.3 & 0.6 & 0.3 & 17.9 & 67 & 8.7 \\
\hline & & 1 & 27.2 & 16.3 & 1.2 & 1.1 & 0.7 & 19.3 & 71 & 7.9 \\
\hline & & 2 & 36.4 & 1.3 & 11.4 & 13.6 & 1.2 & 27.5 & 75 & 8.9 \\
\hline & & 4 & 47.6 & 1.1 & 12.9 & 15.8 & 6.5 & 36.3 & 76 & 11.3 \\
\hline & & 8 & 50.6 & 0.9 & 2.3 & 10.9 & 5.5 & 19.6 & 38 & 31 \\
\hline \multirow[t]{10}{*}{ SiMAG/CS-NTA/Nickel } & His-ProT & 0.5 & 11.2 & 0 & 0 & 0 & 0 & 0 & 0 & 11.2 \\
\hline & & 1 & 17.7 & 3.4 & 0.1 & 0.1 & 0.1 & 3.7 & 21 & 14 \\
\hline & & 2 & 33 & 5.2 & 3.1 & 1.6 & 1.8 & 11.7 & 35 & 21.3 \\
\hline & & 4 & 63.4 & 8.6 & 19.1 & 9.2 & 2.5 & 39.4 & 62 & 24 \\
\hline & & 8 & 65.7 & 12.8 & 14.9 & 3.9 & 1.9 & 33.5 & 51 & 32.2 \\
\hline & His Mre11 & 0.5 & 12 & 0.5 & 1 & 1.2 & 4.1 & 6.8 & 57 & 5.2 \\
\hline & & 1 & 33.5 & 0.8 & 1.2 & 8.9 & 13.5 & 24.4 & 73 & 9.1 \\
\hline & & 2 & 46 & 4.1 & 2.6 & 11.7 & 18.5 & 36.9 & 80 & 9.1 \\
\hline & & 4 & 63.9 & 4.1 & 2.6 & 11.7 & 27.4 & 45.8 & 72 & 18.1 \\
\hline & & 8 & 65.7 & 4.1 & 2.6 & 11.7 & 27.3 & 45.7 & 69 & 20 \\
\hline
\end{tabular}

$\mathrm{E}_{1}-\mathrm{E}_{4}$ are imidazole concentration for elution of recombinant proteins ranging from $0.25,0.5,1$ to 2 and $0.05,0.1,0.25$ to 0.5 molar (M), For SiMAC-Nickel beads and SiMAG/N-NTA/Nickel or SiMAG/CS-NTA/Nickel, respectively. Specific binding capacity: Percent of band density in flowthrough fraction (FT) for each bead concentration subtracted from $100 \%$ was defined as Specific binding capacity. Yield: was defined as the sum of the percents of the specific band densities at four elution steps (E1-4). Recovery: was calculated as the percent of purification yield divided by Specific binding capacity. Protein loss: The sum of the percents of specific band densities in four wash steps (W1-4) and residual fraction (RF) was defined as protein loss.

expected, the higher the concentration of beads, the higher fraction of the protein remained attached to the matrix (Figure 5).

\section{Effect of bead concentration}

In order to clarify the effect of bead concentration on the purification efficacy, different concentrations of beads were examined. As shown in Table 1, specific binding capacity of the beads for both recombinant proteins was increased considerably by increasing their concentrations. Moreover, in the case of SiMAC-Nickel there was a direct relationship between the bead concentration and the concentration of imidazole solution required for protein elution (Figure 5). More importantly, the higher the bead concentration, the more protein remained uneluted even after the application of the highest concentration of elution buffer (Table 1 and Figure 5). Furthermore, the purity analysis of eluted proteins by SDS-PAGE and subsequent silver staining showed that at bead concentrations greater than $4 \mathrm{mg} / \mathrm{ml}$ several contaminating proteins were present in addition to target His-tagged protein. This analysis showed that usage of lower concentration of the beads during binding process may reduce relative percentage of non-specific protein adsorption and thereby increases the purity. Nevertheless, when the bead concentration was further decreased, the purification yield was decreased in parallel.

$4 \mathrm{mg} / \mathrm{ml}$ of SiMAG/N-NTA/Nickel bead resulted in the best purification result in terms of both yield and recovery for His-ProT. The same concentration of 


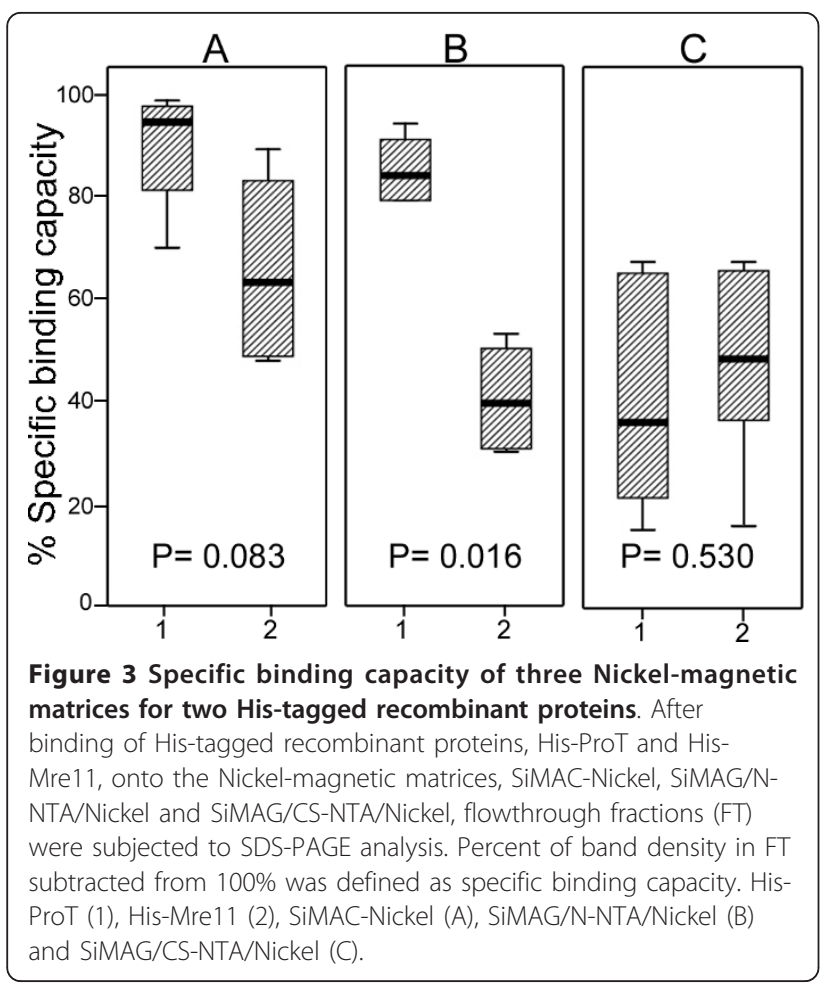

SiMAC-Nickel bead was efficient for purification of HisProT as well, but higher concentrations of imidazole were needed the protein to be recovered (Table 1 and Figure 5).

\section{Verifying the purified His-tagged Proteins by Western blotting}

The recombinants His-ProT and His-Mre11 in the eluate had molecular masses of about 20 and $100 \mathrm{kDa}$, respectively, when analyzed by SDS-PAGE. As representative for all matrices, purified proteins from SiMAG/NNTA/Nickel beads were also characterized using specific antibodies by Western blotting which showed the expected bands as depicted in Figure 7.

\section{Discussion}

Magnetic-based His-tag affinity matrices have been widely used for the purification of recombinant proteins from various overexpression systems $[4,5,15]$. Given their wide application in protein purification, setting the optimal conditions up to achieve the best recovery, yield and purity covering the wide range of recombinant proteins is a prerequisite. In most instances, however, general procedures are usually described, not pointing to the details of methodology in terms of optimal matrix: lysate ratio, elution conditions, purification quality or final yield. This is mostly true for newly-released commercial matrices which are not supported by the existing data in the literature. Although, it is believed that the purity and yield of such procedures depend to some extend on the protein itself $[4,11]$, evaluation of the procedure itself deserve to be performed extensively. The present study evaluated three new commercial magnetic matrices quantitatively and qualitatively and compared their efficacy for purification of the two recombinant His-tagged proteins, ProT and Mre11.

Our observations showed that these matrices give considerably different purity, yield, and have different specific binding capacity and recovery. Evaluation of flowthrough fractions clearly showed that besides protein of interest, SiMAC-Nickel matrix adsorbs unrelated proteins as well from the expression system. It is notable that SiMAC-Nickel matrices are porous in nature, a

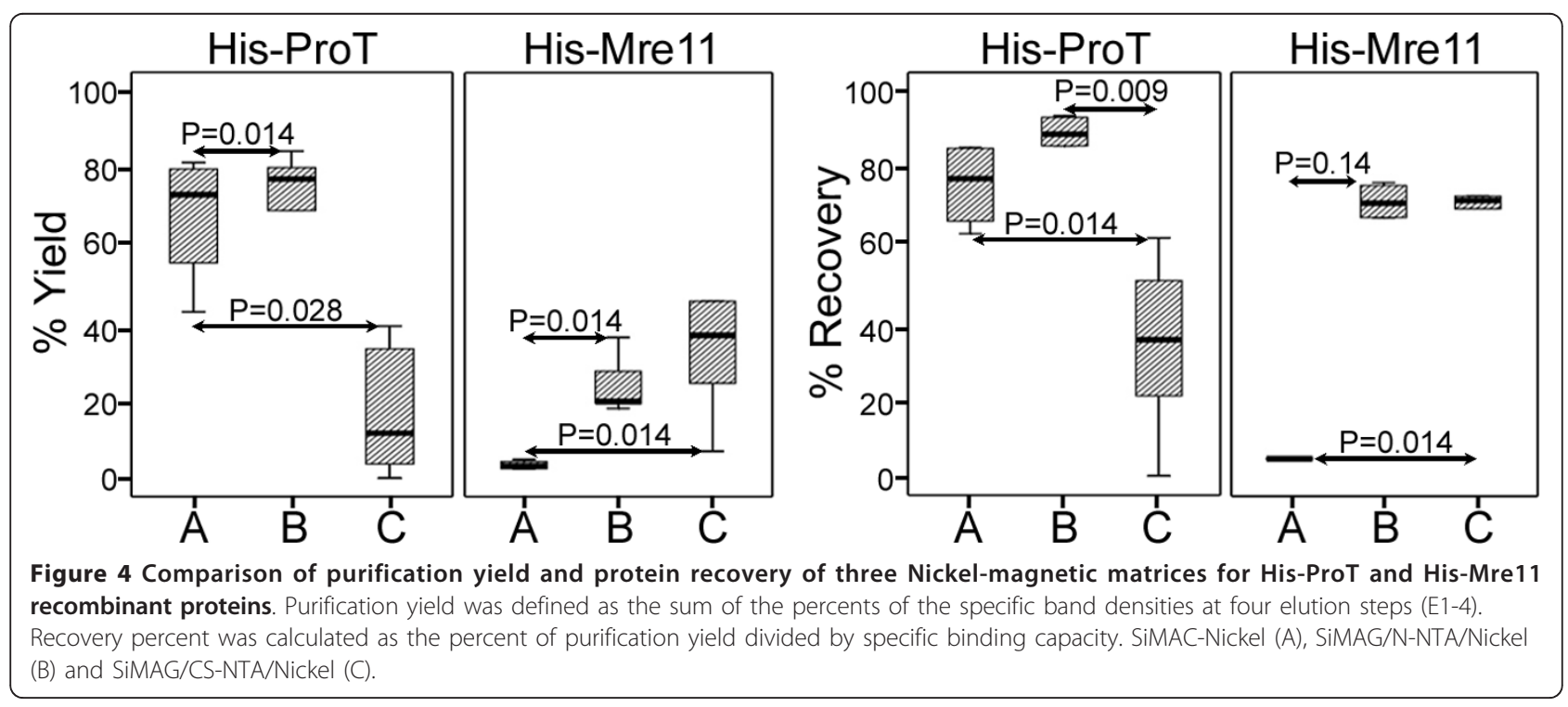




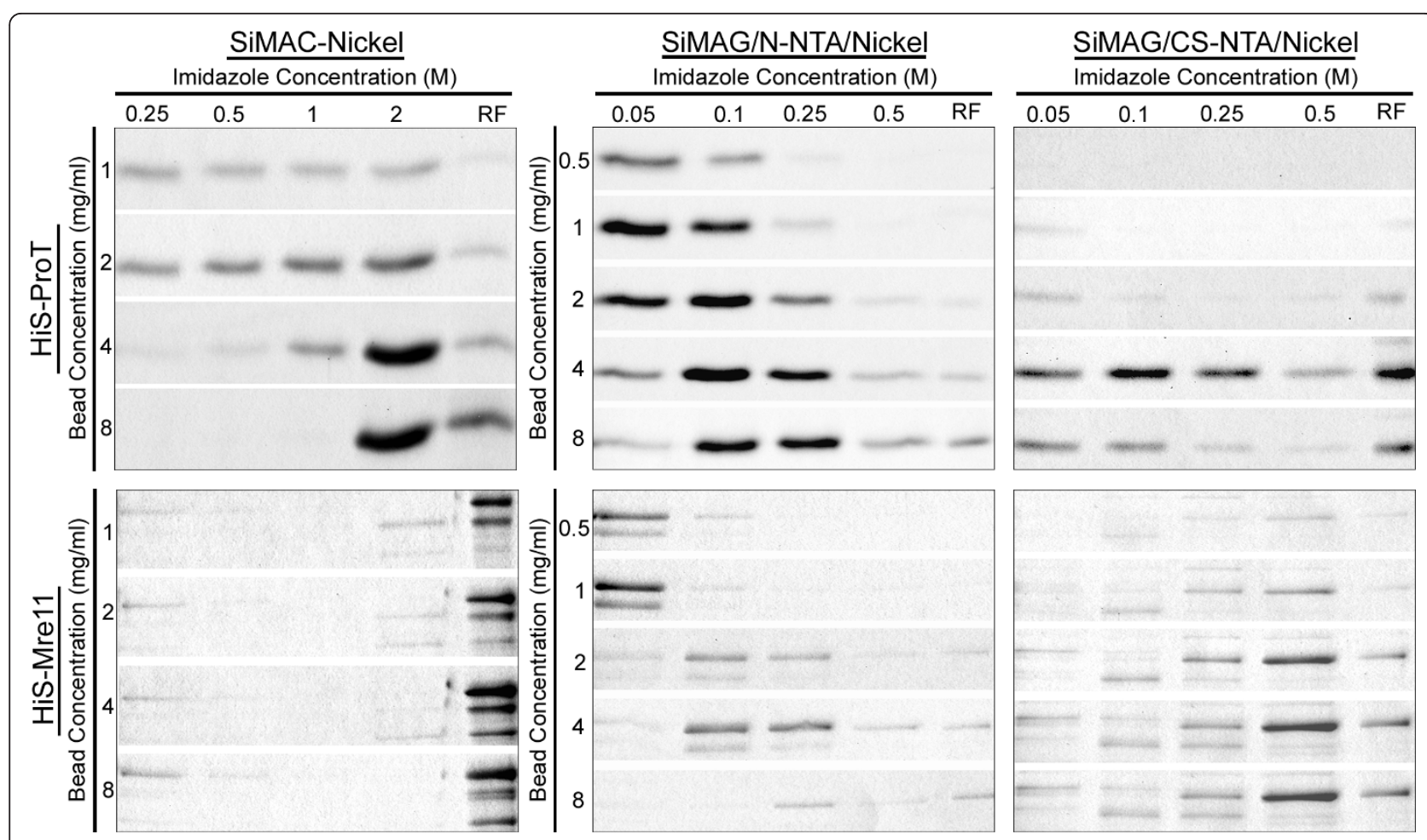

Figure 5 Effect of imidazole concentration on elution of recombinant proteins from three Nickel magnetic matrices. His-ProT and HisMre11 recombinant proteins were bound onto the different concentrations of SiMAC-Nickel, SiMAG/N-NTA/Nickel and SiMAG/CS-NTA/Nickel magnetic matrices. Elution fractions collected by increasing concentrations of imidazole were subjected to SDS-PAGE analysis. RF: Residual fraction.

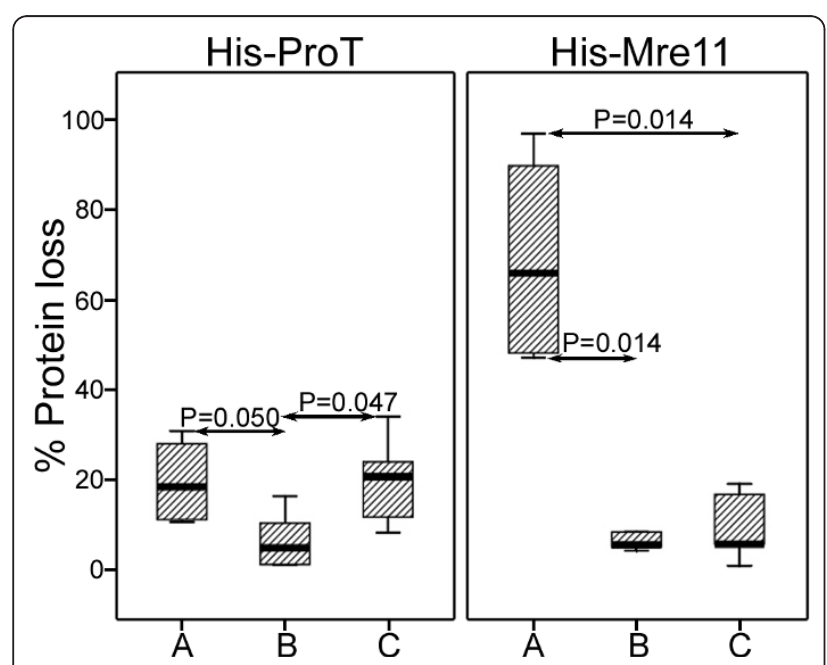

Figure 6 Percent loss of target recombinant proteins purified by three Nickel magnetic matrices. Percent of the recombinant proteins, His-ProT and His-Mre11, lost during purification process by SiMAC-Nickel, SiMAG/N-NTA/Nickel and SiMAG/CS-NTA/Nickel magnetic matrices was calculated as described in materials and methods. Comparison was made between three matrices for each protein. SiMAC-Nickel (A), SiMAG/N-NTA/Nickel (B) and SiMAG/CSNTA/Nickel (C). character which may explain their extra ordinary nonspecific adsorptive capacity for irrelevant proteins. In line with this finding, Franzerb et al. [7] proposed that matrix should be non-porous with respect to the target

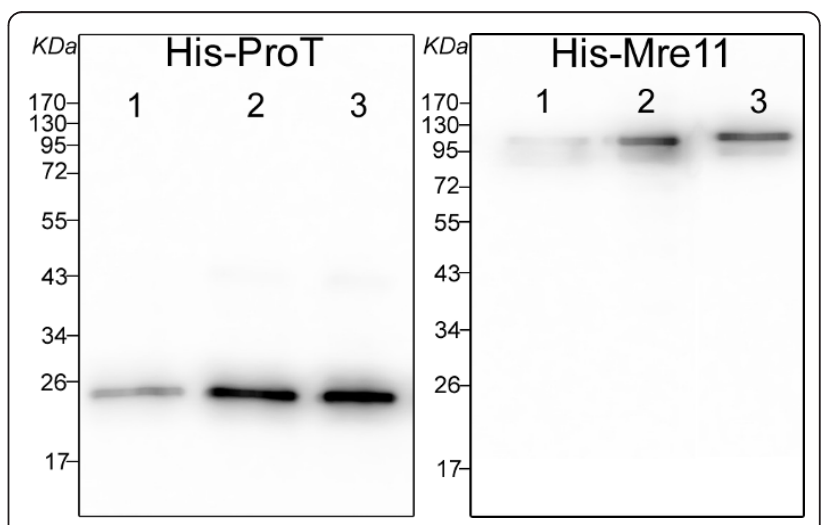

Figure 7 Western blot analysis of purified His-ProT and HisMre11 recombinant proteins. Elution fractions of His-ProT and His-Mre11 recombinant proteins purified by $4 \mathrm{mg} / \mathrm{ml}$ SiMAG/N-NTA/ Nickel magnetic matrix were subjected to SDS-PAGE. Bands were transferred to nitrocellulose membrane and specific bands were detected by antibodies directed against $6 \mathrm{His}$ tag by ECL system. 1-3 indicated the fractions eluted by $0.05,0.1$ and $0.25 \mathrm{M}$ imidazole, respectively. 
biomolecules. On the other hands, this matrix is consisted of a magnetic core and a nickel-silica composite matrix with the nickel ions tightly integrated in the silica [11] and so, in contrast to NTA-coupled matrices, all valences of $\mathrm{Ni}$ are available for histidine binding. This may result in increased binding to His-like endogenous proteins as impurities. Thus, it seems that the surface chemistry of the matrix is an important determinant which affects the degree of non-specific interactions. Indeed, the percent of non-specific binding was not only influenced by the type of the matrix, but apparently depended on the nature of the His-tagged protein as well (See Figure 5). We encountered minimal problem with purification of His-ProT and in this case the impurities were minimal as well, but with Mre-11, which is a high MW protein, not only the purification efficacy was low, but there was a considerable amount of non-specific proteins eluted in conjunction with this protein. Final purity of the purified proteins is without any doubt an excellent measure of the performance of protein purification systems. In this regard, SiMAG/NNTA/Nickel showed superior quality over the SiMAG/ CS-NTA/Nickel. Specific binding performance of the matrixes for ProT and Mre11 also showed great variation. This is mainly influenced by the type of the matrix. One determining factor which affects both specific banding capacity, \% yield and recovery is the affinity of interaction between matrix and the protein of interest which in turn is determined by the number of coordination bands available in the matrix. According to the information provided by the manufacturer, SiMAG/CSNTA, and SiMAG/N-NTA are synthesized by a onestep coupling procedure of Nitrilotriacetic acid (NTA) to SiMAG-Carboxyl via EDC [1-Ethyl-3-(3-dimethylaminopropyl) carbodiimid] activation. The difference between SiMAG/N-NTA/Nickel and SiMAG/CS-NTA/ Nickel is caused in part by a different carboxylation degree of the starting material; SiMAG-Carboxyl. NTA adsorbents including SiMAG/CS-NTA and SiMAG/NNTA are quadridentate chelate former and form four coordination bands with such metal ions as Nickel. Regarding the fact that $\mathrm{Ni}$ has six valencies, only two valences remain unoccupied for reversible binding to histidine [3]. This may explain the higher affinity and binding capacity of SiMAC-Nickel, which has six coordination bounds available for histidine binding, compared to the other two NTA-based matrices.

Collectively, SiMAG/CS-NTA/Nickel showed lower specific binding capacity compared to the other beads. Such limitation should be overcome if the costs of recombinant protein production are to be lowered.

As a matter of fact, a purification system should give as high yield as possible with high recovery and could be applicable to a broad range of proteins. A purification system working well only on a specific group of proteins could not be desirable. In this context, SiMAC-Nickel matrices were inferior to both SiMAG/ N-NTA/Nickel and SiMAG/CS-NTA/Nickel matrices because it was unable to recover the majority of Mre11. Although, both Mre11 and ProT were recovered by SiMAG/N-NTA/Nickel and SiMAG/CS-NTA/Nickel beads, SiMAG/N-NTA exhibited superior capacity when $\%$ recovery for both proteins was concerned. Three matrices also showed variable yields with similar pattern as recovery. As a whole, SiMAG/N-NTA/Nickel bead was superior in terms of both yield and recovery regardless of the type of protein.

Another important factor which should be taken in mind for all protein purification systems is the strength needed for elution of the proteins from matrix. The harsher the elution condition, the more likely protein loses its structure and function. Our data showed that higher concentration of imidazole is needed the proteins to be eluted from SiMAC-Nickel beads. This was in contrast with the elution pattern of SiMAG/N-NTA/ Nickel matrices in which lower concentrations of imidazole were quite sufficient for proteins elution. These differences can be attributed to the higher affinity of SiMAC-Nickel beads to the His-tagged proteins compared to the NTA-coupled matrices. Therefore, on the view of elution conditions, SiMAG/N-NTA/Nickel matrices were superior as well.

In contrast to what has been reported earlier [11], our results showed that higher concentration of the matrix, binding more His-tagged proteins doesn't usually lead to the best yield and purification results. This conclusion was supported by the fact that higher concentrations of imidazole, which can disrupt macromolecular complexes, were required to elute out the majority of Histagged proteins from the beads when higher concentrations of the beads were used (more than $4 \mathrm{mg} / \mathrm{ml}$ ). At this high bead concentration, a fraction of His-tagged protein was still remained bound to the matrices after multiple imidazole elutions which resulted in lower yield. The reason for this notion is that with higher bead concentrations, higher $\mathrm{Ni}$ ions would be accessible to interact with histidine moieties on recombinant protein which in turn strengthen the affinity of interaction. This may lead the His-tagged protein to be remained bound to the beads after elution step [19]. Indeed, at higher bead concentrations non-target proteins (including His-tag like endogenous host and hydrophobic proteins which bind to $\mathrm{Ni}$ ions and matrix of beads, respectively) contaminated the protein of interest in the eluate.

As a result, application of optimal bead concentration during protein binding (here $4 \mathrm{mg} / \mathrm{ml}$ ) may not only increases the purity of target protein by leaving fewer 
opportunities for both His-tag like endogenous and other non-specific host proteins to be bound onto the nickel ions and matrix itself, respectively, but may improve the quality of purified recombinant protein by allowing lower concentrations of imidazole to be used for elution. It should be noted that when the bead concentration is further decreased, His-tagged proteins are lost during wash steps.

Therefore, it should be taken in mind that purification indices are completely interrelated with positive and negative impacts on each other and a compromise should be made for selection of the best purification system. Taken together, we conclude that SiMAG/N-NTA/ Nickel would be the matrix of choice to get uniform results for different His-tagged proteins.

Until now several helpful hints have been proposed to obtain good results in magnetic separations of proteins and peptides [15]. The provided information in this report could be viewed as a clue helping researchers to overcome obstacles raised during purification of His-tagged recombinant proteins by Nickel-coated magnetisable matrices.

\section{Conclusions}

Protein purification using magnetisable solid phase supports have still been accompanied by some fundamental drawbacks. The extent of specific binding capacity, purity, yield and recovery vary from one matrix to another. This variability is a function of structure and surface chemistry of the matrix which are determining factors for affinity of interaction. It is also influenced to a lesser extent by the physical properties of the protein, itself. The present paper represents a reliable methodology for assessment of functionality of different nanomagnetic matrices working with the same principle. And more importantly, points to step by step optimization procedure for purification of Histagged recombinant proteins. Although the results of the present study may not be fully applied for all nanomagnetic matrices, but provide a framework which could be used to profiling and quantitative evaluation of other magnetisable matrices, especially those useable for His-tagged protein purification. The final goal is, without any doubt, manufacturing a versatile nanomagnetic matrix and introducing an optimized protocol functioning over a majority of recombinant proteins. In this context, devoting further research efforts on production and optimizing of such nanomagnetisable matrices is a necessity which would help to give new insights for developing versatile and userfriendly resins suitable for purification of a vast array of recombinant His-tagged proteins.

\section{Methods}

\section{Instruments}

Magnetic separation stand and permanent magnet separator were purchased from Promega company
(Madison, WI USA). Other major instruments used in this study were: GFL 3033 (Burgwedel, Germany) and SHEL Lab (Oregon, USA) shaking incubators for bacterial culture and recombinant protein expression, Sonoplus HD 2070 sonicator (Bandelin, Berlin, Germany) for bacterial cell lysis, UV/Visible Biophotometer (Ependorf, Hamburg, Germany) for Bradford assay, Eppendorf $5810 \mathrm{R}$ and 5415R refrigerated centrifuges, and Bio-Rad electerophoresis system for sodium dodecylsulfate-polyacrylamide gel electrophoresis (SDS-PAGE) (Bio-Rad Laboratories, California, USA).

\section{Chemicals}

New versions of the Nickel-Magnetic beads: SiMACNickel, SiMAG/N-NTA/Nickel and SiMAG/CS-NTA/ Nickel were purchased from Chemicell company (Berlin, Germany) (Table 2). Chemicals used were of molecular biology grade. DTT, TEMED, Acrylamide/bis-acrylamide and PMSF were purchased from Sigma (St Louis, Mo., U.S.A). The expression vector $\mathrm{pET} 19 \mathrm{~b}$ and E. coli strain BL21 (DE3) were purchased from New England BioLabs (Ontario, Canada), DNase I and RNase A were from Roche applied science (Penzberg, Germany). Isopropyl ß-thiogalactopyranoside (IPTG) was from Gibco (Gaithersburg, MD, USA). Imidazole was from USB (Cleveland, OH, USA). The prestained protein ladder consisting of different arrays of molecular weights 170 , 130, 95, 72, 56, 43, 34, 26, 17 and $11 \mathrm{kDa}$ was from Fermentas (St. Leon-Rot, Germany). Reagents for Bradford protein assay were purchased from Bio-Rad Laboratories (Bio-Rad Laboratories, California, USA). All other chemicals were from Sigma-Aldrich unless otherwise stated.

\section{Recombinant Proteins to be purified}

Two different recombinant proteins with six histidine residues (His-tag) in their C-terminus, ProT and Mre11, with molecular weights of about 25 and $100 \mathrm{KD}$, respectively, were chosen to be separated using the Nickelcoated magnetic beads. Both proteins were expressed in to the bacterial cytosol.

\section{Growth of bacteria and induction of gene expression}

The expression plasmids, pET19b/Mre11 and pET19b/ ProT were prepared and transformed into E. coli BL21 (DE3) as host strain. The Mre11, is a central part of a multisubunit nuclease composed of Mre11, Rad50 and

Table 2 Characteristics of magnetic nanomatrices used in this study

\begin{tabular}{lcc}
\hline Beads Name & Concentration & Functional group group \\
\hline SiMAC-Nickel & $100 \mathrm{mg} / \mathrm{ml}$ & Silica-nickel \\
SiMAG/N-NTA/Nickel & $50 \mathrm{mg} / \mathrm{ml}$ & NTA- nickel \\
SiMAG/CS-NTA/Nickel & $50 \mathrm{mg} / \mathrm{ml}$ & NTA- nickel \\
\hline
\end{tabular}


Nbs1 (MRN) [20]. The MRN complex plays a critical role in sensing, processing and repairing DNA double strand breaks [21]. Three millilitres of SOB medium [5.0 $\mathrm{g}$ tryptone, $1.25 \mathrm{~g}$ yeast Extract, $0.125 \mathrm{~g} \mathrm{NaCl}, 0.0465 \mathrm{~g}$ $\mathrm{KCl}$ per $250 \mathrm{ml}$ water, $\mathrm{pH} 7.0$ containing ampicillin (100 $\mu \mathrm{g} / \mathrm{ml})$ ] were inoculated with a single colony of the transformed BL21(DE3) and grown overnight at $37^{\circ} \mathrm{C}$ with shaking at $225 \mathrm{rpm}$. The next day, $12 \mathrm{ml}$ of prewarmed $\mathrm{SOB}$ medium were inoculated with the overnight culture medium until the final OD600 $\mathrm{nm}$ was reached to 0.1 [having the OD600 $\mathrm{nm}$ of about 4-5, 250 $\mu \mathrm{l}$ of the overnight culture in $12 \mathrm{ml}$ of fresh SOB medium gave an OD of 0.1]. The culture was grown at $37^{\circ} \mathrm{C}$ with shaking at $225 \mathrm{rpm}$ to an OD600 nm of 0.4-0.5. At this point, protein expression was induced by $12 \mu \mathrm{l}$ of 1 $\mathrm{M}$ IPTG to give a final concentration of $1 \mathrm{mM}$. The induced culture was continued for 4 hours and then processed for protein extraction. During the expression processes, a sample of $250 \mu \mathrm{l}$ was taken at the end of each hour for SDS-PAGE analysis.

\section{Cell lysis and protein extraction}

Bacterial cells were harvested by centrifugation of cell culture at $4000 \mathrm{rpm}, 4^{\circ} \mathrm{C}$ for $10 \mathrm{~min}$. Supernatant was aspirated off and cells were washed three times with cold binding-wash solution ( $20 \mathrm{mM} \mathrm{Na} \mathrm{HPO}_{4}, \mathrm{pH}$ 7.0). Cells were then resuspended in $2 \mathrm{~mL}$ cold lysis buffer (20 mM Na${ }_{2} \mathrm{HPO}_{4}, 10 \mathrm{mM}$ imidazole, $\mathrm{pH} 7.0,1 \mathrm{mM}$ PMSF, and $27 \mathrm{mM}$ lysozyme) and incubated on ice for 30 minutes. Cell lysis was further continued by sonication $(10 \mathrm{~s}$ at $70 \%$ power, four times, 1 min intervals at $4^{\circ} \mathrm{C}$ with a M73 probe). The lysate was centrifuged at $12000 \mathrm{rpm}, 4^{\circ} \mathrm{C}$ for $10 \mathrm{~min}$ and $1 \mathrm{ml}$ of supernatant was transferred into a $1.5-\mathrm{mL}$ eppendorf tube. At the next step, RNase A and DNase I $(0.125 \mu \mathrm{g} / \mathrm{ml}$ and $3 \mathrm{Unit} / \mathrm{ml}$ final concentrations, respectively) were added and incubation was continued on ice for 10-15 minutes. After centrifugation at $13000 \mathrm{rpm}$ for $10 \mathrm{~min}, 4^{\circ} \mathrm{C}$, supernatant was filtered through a $0.2 \mu \mathrm{m}$ cellulose acetate filter (Millipore, USA) before mixing with Nickel-coated magnetic beads.

\section{Estimation of total protein concentration}

The protein concentration of filtered soluble cell extract (SCE) was estimated by spectrophotometric analysis at $280 \mathrm{~nm}$ in an UV/Visible biophotometer and confirmed by Bradford assay [22] using bovine serum albumin as standard.

\section{Protein Purification by Nickel-coated magnetic beads}

Different amounts of Nickel-coated magnetic beads [5, 10, 20 and $40 \mu \mathrm{l}$ of SiMAC-Nickel bead $(100 \mathrm{mg} / \mathrm{ml})$ corresponding to the final concentration of $1,2,4$ and 8 $\mathrm{mg} / \mathrm{ml}$, respectively, and $5,10,20,40$ and $80 \mu \mathrm{l}$ of
SiMAG/N-NTA/Nickel and SiMAG/CS-NTA/Nickel beads $(50 \mathrm{mg} / \mathrm{ml})$ corresponding to the final concentration of $0.5,1,2,4$ and $8 \mathrm{mg} / \mathrm{ml}$, respectively] were transferred to eppendorf tubes. Tubes were placed on a magnet until the beads migrated to the side of the tube and the clarified liquids were discarded. The beads were washed and equilibrated three times with $500 \mu \mathrm{l}$ of cold lysis buffer. Meantime, soluble cell extracts were diluted to a final concentration of $1.5 \mathrm{mg} / \mathrm{ml}$ with cold lysis buffer before mixing with beads. Diluted SCE was added to the beads in final volume of $700 \mu \mathrm{l}$. The mixture mixed well by gentle pipetting and incubated for 30 minutes on a roller mixer (Behdad Roller Mixer, Tehran, Iran) at $4^{\circ} \mathrm{C}$ for protein binding. After the binding process, tubes were placed in the magnetic separator, and except a small volume $(30 \mu \mathrm{l})$ of the clarified supernatant which was collected and frozen for further analysis as flowthrough samples (FT); the rest was removed and discard. Wash steps were performed 4 times by adding 500 $\mu \mathrm{l}$ of wash buffer $\left(50 \mathrm{mM} \mathrm{NaH} \mathrm{PO}_{4}, 300 \mathrm{mM} \mathrm{NaCl}, 10\right.$ $\mathrm{mM}$ imidazole, $\mathrm{pH}$ 8.0), gentle pipitting and mixing on a roller mixer each for $5 \mathrm{~min}$. At each washing steps, a small portion of supernatant was collected (W1-4) and the rest was discarded. After four washing steps, the entrapped His-tagged proteins were eluted with $200 \mu \mathrm{l}$ of elution buffers $\left(50 \mathrm{mM} \mathrm{NaH} \mathrm{PO}_{4}, 300 \mathrm{mM} \mathrm{NaCl}\right.$ containing different concentrations of imidazole 250 $\mathrm{mM}, 500 \mathrm{mM}, 1 \mathrm{M}$ or $2 \mathrm{M}$ imidazole, $\mathrm{pH} 8.0$ for SiMAC-Nickel bead and $50 \mathrm{mM}, 100 \mathrm{mM}, 250 \mathrm{mM}$ and $500 \mathrm{mM}$ imidazole for SiMAG/N-NTA/Nickel and SiMAG/CS-NTA/Nickel beads). Briefly, $200 \mu \mathrm{l}$ of elution buffer was added to the beads and mixed as above. After magnetic separation, the clarified liquid containing the eluted His-tagged protein were transferred into microtubes followed by centrifugation at $12000 \mathrm{rpm}$ for 3 minutes. Supernatant from each elution steps (E1-4) was then collected and stored at $-20^{\circ} \mathrm{C}$. To evaluate the elution efficacy, the beads pellet was admixed with 500 $\mu \mathrm{l}$ of $1 \times$ SDS-PAGE loading buffer $(50 \mathrm{mM}$ Tris- $\mathrm{HCl}$ pH $6.8,10 \%$ glycerol, $2.5 \%$ SDS, $0.1 \%$ bromophenol blue, $25 \mathrm{mM}$ Dithiothreitol), boiled for $5 \mathrm{~min}$ and subjected to SDS-PAGE as residual fraction (RF).

\section{SDS- PAGE and Western blotting}

SDS-PAGE analysis was performed based on Laëmmli protocol [23]. Samples [soluble cell extract (SCE), flowthrough (FT), washes (W1-4) and elutions (E1-4)] were prepared by mixing $30 \mu \mathrm{l}$ aliquots of each preparation with $7 \mu \mathrm{l}$ of $5 \times$ loading buffer. The samples were boiled for three minutes and spinning down. Then $30 \mu \mathrm{l}$ of supernatants in conjunction with $30 \mu \mathrm{l}$ of residual fractions were loaded on $10-12 \%$ polyacrylamide gel. In case of E.coli cultures for recombinant protein expression, samples of $250 \mu \mathrm{l}$ were collected during different 
intervals of induction process, centrifuged and the pellets were directly suspended in $150 \mu \mathrm{l}$ of $5 \times$ loading buffer, shacked vigorously and then processed as above. Prestained protein ladder was used as molecular weight marker. Electrophoresis was performed in a Mini-Protean II apparatus (Bio-Rad Laboratories, Hercules, CA, USA) with running buffer composed of $25 \mathrm{mM}$ Tris$\mathrm{HCl} \mathrm{pH}$ 8.3, $192 \mathrm{mM}$ glycine, 0.1\% SDS. After separation, gels were stained with silver nitrate. Western blot analysis was carried out according to the protocol we published elsewhere [24] with some modifications. Briefly, after transfer onto nitrocellulose membranes, blocking was done overnight in 5\% skimmed milk followed by three washes with TBS-TT $(20 \mathrm{mM}$ Tris base, $500 \mathrm{mM} \mathrm{NaCl}, 0.1 \% \mathrm{v} / \mathrm{v}$ Tween $20,0.4 \% \mathrm{v} / \mathrm{v}$ Triton x100 PH, 7.5), each for $10 \mathrm{~min}$. Goat anti-His6 monoclonal antibody (Invitrogen, California, USA) and rabbit anti-Mre11 and anti-ProT polyclonal antibodies (Produced in our laboratory) were applied to the membrane at $1: 3000$ as primary antibody for $1.5 \mathrm{~h}$ followed by 1:3000 dilution of hoarse-radish peroxidase (HRP)-conjugated rabbit anti-goat or sheep anti-rabbit (Avicenna Research Institute, Tehran, Iran) for $1 \mathrm{~h}$. Membrane was then washed as above and specific bands were developed by enhanced chemiluminiscent (ECL) system (GH Healthcare, Buckinghamshire, UK) according to the manufacturer's instruction using X-ray film processor (HOPE Micro-Max, Warminster, USA).

\section{Densitometric analysis}

Silver-stained SDS-PAGE gels were scanned and density of specific bands for two recombinant proteins from samples collected at different purification steps (FT, W1-4, E1-4 and residual fraction) in five separate experiments was analyzed using the program AlphaEase FC Software (Version 5.0.1) with standard settings. The method of densitometry we employed was based on calculation of AUC (area under curve) which is based on both band density (height of the curve) and band area (width of the curve). This integrated density value normally offsets the possible mistakes which may be encountered when only band density is concerned. For each individual purification, the sum of the specific band densities from aforesaid fractions was set to $100 \%$ and relative percent of each band was calculated accordingly. The expression rate of each recombinant protein in the soluble fraction of cell lysate was determined by densitometric analysis as the percent of specific band to the all bands observed in SDS-PAGE gel.

\section{Determination of protein purification efficacy}

Four indices including specific binding capacity, purification yield, and percent of protein recovery and loss were determined for each Nickel-magnetic matrix, each bead concentration and each recombinant protein. The sum of the specific band densities from FT, W1-4, E1-4 and RF were set to $100 \%$. Percent of band density in FT subtracted from $100 \%$ was defined as specific binding capacity. Purification yield was defined as the sum of the percents of the specific band densities at four elution steps (E1-4). Recovery percent was calculated as the percent of purification yield divided by specific binding capacity. The sum of the percents of specific band densities in W1-4 and RF was defined as protein loss.

\section{Statistical Analysis}

Numerical data analysis was done using SPSS software version 13.0 (SPSS Inc., Chicago, Illinois). Two-tailed statistical analyses were performed using the SPSS software version 13.0. Percent of bound, lost and eluted fractions of each protein was calculated for five individual experiments for each matrix and compared by Mann-Whitney test with Bonferroni correction. P-values less than 0.05 were considered significant.

\section{Acknowledgements}

The authors would like to thank Avicenna Research Institute for financial support and declare no conflict of interest in this research work. We also appreciate all our colleagues listed in the references for proving invaluable information which helped us to perform this research. We thank also Chemicell company for providing information on the structure and surface chemistry of the matrices.

\section{Author details}

${ }^{1}$ Nanobiotechnology Research Center (NBRC), Avicenna Research Institute, ACECR, Tehran, Iran. ${ }^{2}$ Monoclonal Antibody Research Center (MARC), Avicenna Research Institute, ACECR, Tehran, Iran. ${ }^{3}$ Immunology Research Center, Tehran University of Medical Sciences, Tehran, Iran.

\section{Authors' contributions}

The authors meet the criteria for authorship as follows: MRN has made substantial contribution to design, acquisition of data and manuscript drafting. MC has made substantial contribution to conception and design. SZ has participated in data analysis and AHZ has involved in methodology design, interpretation of data, critical revision of the manuscript and final approval of the version to be published.

\section{Competing interests}

The authors declare that they have no competing interests.

Received: 21 February 2011 Accepted: 8 August 2011

Published: 8 August 2011

\section{References}

1. Porath J, Carlsson J, Olsson I, Belfrage G: Metal chelate affinity chromatography, a new approach to protein fractionation. Nature 1975, 258:598-599.

2. Hochuli E, Bannwarth W, Doebeli H, Gentz R, Stueber D: Genetic Approach to Facilitate Purification of Recombinant Proteins with a Novel Metal Chelate adsorbent. BioTechnology 1988, 1321-1325.

3. Hochuli E, Doebeli $H$, Schacher A: New metal chelate adsorbent selective for proteins and peptides containing neighbouring histidine residues. $J$ Chromatogr B Analyt Technol Biomed Life Sci 1987, 411:177-184.

4. Cao H, Lin R: Quantitative Evaluation of His-Tag Purification and Immunoprecipitation of Tristetraprolin and Its Mutant Proteins from Transfected Human Cells. Biotechnology Progress 2010, 25:461-467. 
5. Gaber-Porekar V, Menart V: Potential for using histidine tags in purification of proteins at large scale. chemical engineering technology 2005, 28:1306-1314.

6. Xu C, Xu K, Gu H, Zhong X, Guo Z, Zheng R, Zhang X, Xu B: Nitrilotriacetic acid-modified magnetic nanoparticles as a general agent to bind histidine-tagged proteins. J Am Chem Soc 2004, 126:3392-3393.

7. Franzreb M, Siemann-Herzberg M, Hobley TJ, Thomas OR: Protein purification using magnetic adsorbent particles. Appl Microbiol Biotechnol 2006, 70:505-516.

8. Graslund S, Nordlund P, Weigelt J, Hallberg BM, Bray J, Gileadi O, Knapp S, Oppermann U, Arrowsmith C, Hui R, et al: Protein production and purification. Nat Methods 2008, 5:135-146.

9. Abudiab T, Beitle RR Jr: Preparation of magnetic immobilized metal affinity separation media and its use in the isolation of proteins. $J$ Chromatogr A 1998, 795:211-217.

10. Feczko T, Muskota A, Gal L, Szepvolgyi J, Sebestyen A, Vonderviszt F: Synthesis of Ni-Zn ferrite nanoparticles in radiofrequency thermal plasma reactor and their use for purification of histidine-tagged proteins. Journal of Nanoparticle Research 2008, 10:227-232.

11. Frenzel A, Bergemann C, Kohl G, Reinard T: Novel purification system for 6xHis-tagged proteins by magnetic affinity separation. J Chromatogr $B$ Analyt Technol Biomed Life Sci 2003, 793:325-329.

12. Kim JS, Valencia CA, Liu R, Lin W: Highly-Efficient Purification of Native Polyhistidine-Tagged Proteins by Multivalent NTA-Modified Magnetic Nanoparticles. Bioconjugate Chem 2007, 18:333-341.

13. Lee IS, Lee N, Park J, Kim BH, Yi YW, Kim T, Kim TK, Lee IH, Paik SR, Hyeon T: $\mathrm{Ni} / \mathrm{NiO}$ core/shell nanoparticles for selective binding and magnetic separation of histidine-tagged proteins. Journal of the American Chemical Society 2006, 128:10658-10659.

14. Nishiya Y, Hibi T, Oda J-i: A purification method of the diagnostic enzyme Bacillus uricase using magnetic beads and non-specific protease. Protein Expression and Purification 2002, 25:426-429.

15. Safarik I, Safarikova M: Magnetic techniques for the isolation and purification of proteins and peptides. Biomagn Res Technol 2004, 2:1-17.

16. Saiyed Z, Telang $S$, Ramchand C: Application of magnetic techniques in the field of drug discovery and biomedicine. Biomagn Res Technol 2003, 1:2.

17. Sakamoto S, Kabe Y, Hatakeyama M, Yamaguchi Y, Handa H: Development and application of high-performance affinity beads: toward chemical biology and drug discovery. Chemical record 2009, 9:66-85.

18. Smith C: Striving for purity: advances in protein purification. Nature Methods 2005, 2:71-77.

19. Westra DF, Welling GW, Koedijk DGAM, Scheffer AJ, Theb TH, WellingWester S: Immobilised metal-ion affinity chromatography purification of histidine-tagged recombinant proteins: a wash step with a low concentration of EDTA. Journal of Chromatography B 2001, 760:129-136.

20. D'Amours D, Jackson SP: The Mre11 complex: at the crossroads of dna repair and checkpoint signalling. Nat Rev Mol Cell Biol 2002, 3:317-327.

21. Johzuka K, Ogawa H: Interaction of Mre11 and Rad50: two proteins required for DNA repair and meiosis-specific double-strand break formation in Saccharomyces cerevisiae. Genetics 1995, 139:1521-1532.

22. Bradford MM: A rapid and sensitive method for the quantitation of microgram quantities of protein utilizing the principle of protein-dye binding. Analytical Biochemistry 1976, 72:248-254.

23. Laemmli $\mathrm{U}$ : Cleavage of structural proteins during the assembly of the head of bacteriophage T4. Nature 1970, 277:680-685.

24. Jeddi-Tehrani M, Abbasi N, Dokouhaki P, Ghasemi J, Rezania S, Ostadkarampour M, Rabbani H, Akhondi MA, Fard ZT, Zarnani AH: Indoleamine 2,3-dioxygenase is expressed in the endometrium of cycling mice throughout the oestrous cycle. J Reprod Immunol 2009, 80:41-48.

doi:10.1186/1477-3155-9-31

Cite this article as: Nejadmoghaddam et al:: Profiling and quantitative evaluation of three Nickel-Coated magnetic matrices for purification of recombinant proteins: helpful hints for the optimized nanomagnetisable matrix preparation. Journal of Nanobiotechnology 2011 9:31.

\section{Submit your next manuscript to BioMed Central and take full advantage of:}

- Convenient online submission

- Thorough peer review

- No space constraints or color figure charges

- Immediate publication on acceptance

- Inclusion in PubMed, CAS, Scopus and Google Scholar

- Research which is freely available for redistribution

Submit your manuscript at www.biomedcentral.com/submit
Biomed Central 